\title{
O sentimento anti-Japão na China: origens, estímulos e consequências ${ }^{1}$
}

\author{
The anti-Japan sentiment in China: \\ origins, stimulus and consequences
}

DOI: $10.21530 /$ ci.v12n2.2017.633

Hércules Paulino de Souza²

\section{Resumo}

No atual panorama global das relações entre potências, podemos caracterizar a relação entre China e Japão como uma das mais tensas e com grande potencial de conflito. Tal condição deriva dos fatos ocorridos no curso do último século, majoritariamente ligados às invasões japonesas durante as duas guerras sino-japonesas. As agressões japonesas acabaram por fazer do Japão um protagonista na inflição do “século de humilhação” ao povo chinês (1839-1949), ao lado das potências ocidentais, que também submeteram a nação chinesa a conflitos e "tratados desiguais". Às vívidas experiências da violência promovidas pelos japoneses seriam somadas políticas de propaganda, como filmes e canções, demonstrando a expulsão dos "demônios japoneses" pelas forças comunistas, formando sobre tal memória histórica o capital político de libertador nacional do Partido Comunista. Tal sentimento antijaponês perdurou no decorrer das décadas, encontrando terreno fértil para se propagar com o advento das tecnologias de informação vinculadas à internet, ao enfraquecimento da ideologia comunista e à ascensão do nacionalismo. Portanto, pretendemos apresentar como tal sentimento anti-Japão foi fomentado no passado e na atualidade, como convulsionou a população chinesa em determinados momentos da história recente, ao sair do controle do Estado, e suas consequências para a relação sino-japonesa em um momento em que os dois países passam por um período de afirmação no cenário global.

Palavras-chave: China; Japão; sentimento antijaponês; nacionalismo

1 O presente artigo é parte de pesquisa financiada pela CAPES - Coordenação de Aperfeiçoamento de Pessoal de Nível Superior.

2 Programa de Pós-Graduação em Ciências Sociais da Faculdade de Filosofia e Ciências de Marília, Universidade Estadual Paulista - Unesp, Marília/SP, Brasil. E-mail: herculespaulino@gmail.com

Artigo submetido em 12/02/2017 e aprovado em 11/04/2017. 


\begin{abstract}
In the current global picture of relations between powers, we can characterize the relation between China and Japan as one of the most tense and with a great potential for conflict. Such condition derives from the events that took place in the last century, mostly linked to the Japanese invasions during the two Sino-Japanese wars. The Japanese aggressions eventually made Japan a protagonist in the infliction of the Century of Humiliation to the Chinese people (1839-1949), alongside the Western Powers, who also subjected the Chinese nation to conflicts and 'unequal treaties'. To the vivid experiences of the violence promoted by the Japanese would be added propaganda policies, such as movies and songs, demonstrating the 'Japanese demons' expulsion by the communist forces, forming on such historical memory the Communist Party political capital as national liberator. Such antiJapanese sentiment persisted over the decades and found fertile ground to spread with the advent of internet-related information technologies, the weakening of communist ideology and the rise of nationalism. Therefore, we intend to present how such anti-Japan sentiment was fomented in the past and present, how it convulsed the Chinese population at certain moments in recent history when it came out of state control, and its consequences for the Sino-Japanese relation at a time the two countries are going through a period of affirmation on the global stage.
\end{abstract}

Keywords: China; Japan; anti-Japanese sentiment; nationalism

\title{
Introdução
}

A relação sino-japonesa é uma das mais complexas a se analisar no ambiente diplomático atual, assim como é uma das mais importantes em termos econômicos. China e Japão são respectivamente segunda e terceira maiores economias globais, grandes parceiros econômicos, vizinhos muito próximos geograficamente e com uma história recente de conflitos. Recentemente, tal relação se caracteriza por um forte vínculo econômico - tendo a China se tornado maior parceiro comercial do Japão a partir de 2008, e o Japão se consolidado como segundo grande parceiro econômico da China na primeira década do século XXI (SIMOES; HIDALGO, 2011) - porém, tal laço econômico refletiu pouco sobre a evolução positiva da relação diplomática entre as duas nações. Apontar e refletir brevemente sobre essa relação diplomática “fria” entre os dois países é nosso objetivo no presente trabalho.

A relação sino-japonesa é um exemplo importante de como a história pode influenciar consideravelmente e refletir-se de maneira intensa na relação atual e futura entre nações. Para entendermos os motivos dessa frieza política 
que caracteriza a relação, é necessário que olhemos não apenas para os fatos históricos passados que envolveram os dois povos, mas também como parte dos sentimentos gerados por tais acontecimentos foram ora reprimidos, ora fomentados. Desentendimentos bilaterais recentes desencadearam eventos onde ficou evidente a opinião negativa entre os dois povos, e tais divergências não poderão ser entendidas sem buscar origem e motivos para que tais sentimentos perdurem até a atualidade - o que buscamos fazer aqui de forma sucinta.

Como a temática histórica é extensa, abrangendo fatos e memória dos povos chinês e japonês, assim como ações políticas recentes por parte de líderes de ambos os países, optamos por trabalhar aqui apenas com o que se refere à parte chinesa da relação. Na primeira parte do trabalho, optamos por demonstrar os fatos históricos que possibilitaram que o sentimento anti-Japão na China ganhasse força no decorrer das últimas décadas - a evocação desses fatos seria primordial para o discurso de futuros líderes e campanhas patrióticas. Na interpretação que seguimos, as divergências entre China e Japão se evidenciaram já nas formas distintas de reação e adaptação à conjuntura imperialista ocidental que se impunha na Ásia durante o século XIX, tendo os distintos modelos de adaptação levado aos conflitos iniciais entre os dois países. Na segunda parte, demonstramos como ocorreu a reaproximação e normalização da relação sino-japonesa e os impactos pela forma através da qual foi efetuada. Exploramos, ainda, como o sentimento anti-Japão se torna progressivamente um elemento do nacionalismo patriótico chinês, em um ambiente doméstico onde a liderança comunista chinesa necessita de outros elementos - para além da ideologia marxista-leninista - que justifiquem sua legitimidade como governante da China. Por fim, concluímos com uma breve exposição sobre algumas das consequências ocasionadas pelo aumento do sentimento antijaponês entre a população chinesa nas últimas décadas.

O conceito de nacionalismo é utilizado aqui de forma recorrente, e visto sua complexidade em termos de definição e distintas abordagens no campo dos fenômenos sociais, adotamos a elucidação sucinta de Ekman e Pajon como aplicável aos nossos objetivos. Para as autoras, o nacionalismo é um estado de espírito que nutre o sentimento de pertença a um grupo, por meio da mobilização de um conjunto de fatores comuns, incluindo território, valores, idioma, história, identidade e um projeto nacional, sendo também um instrumento político utilizado pelas elites do Estado para mobilizar as massas, assim como por grupos nacionalistas para influenciar as escolhas políticas do governo (EKMAN; PAJON, 2015). 
Aqui também é fundamental frisar que o sentimento anti-Japão na China não é apenas resultado de campanhas patrióticas ou do nacionalismo chinês. Parte importante desse sentimento surge como reação a ações nacionalistas de líderes políticos japoneses, ações consideradas como ofensas às vítimas da invasão japonesa. Aqui citaremos brevemente essas ações da classe política japonesa, buscando esclarecê-las da melhor maneira possível, de forma consoante com a delimitação do tema aqui proposto, propondo-nos a fazer uma discussão do nacionalismo japonês em trabalhos posteriores. Portanto, durante a leitura do trabalho, é necessário ter em mente que grande parte das ações nacionalistas da população chinesa é reação ao nacionalismo fomentado no Japão.

\section{As origens históricas do sentimento anti-Japão na China}

A rivalidade recente entre China e Japão, assim como a origem das desconfianças chinesas em relação à política exterior de Tóquio, encontra suas raízes no desdobramento de eventos de escala global da passagem do século XIX para o século XX.

Em tal período, o imperialismo europeu, que se desenvolvia desde o século XVI, necessitava de maior expansão para sua manutenção. Tendo na expansão geográfica e na exploração das demais regiões do mundo os pilares do acúmulo de poder econômico e militar, as potências europeias - através da articulação do equilíbrio de poder - tiveram a capacidade de formar extensos impérios ultramarinos. Utilizando as riquezas provenientes das Américas, as potências europeias puderam se fortalecer internamente e posteriormente partiriam para a exploração da produção, dos mercados e do comércio asiático (ARRIGHI, 2008). Portanto, uma nova onda expansionista das potências ocidentais, rumo a Ásia e África, se daria com maior intensidade após os movimentos de independência nas Américas, durante o século XIX, e seus impactos econômicos aos Estados e companhias de comércio europeias. Em tal contexto, as sociedades asiáticas seriam abertas por consentimento ou força, como ficou evidente pelas estratégias agressivas e tratados desiguais impostos à China pelas potências ocidentais. O antigo Império Chinês foi submetido a uma série de agressões que seria conhecida como o "século da humilhação chinesa", iniciado em meados do século XIX, tendo a Primeira Guerra do Ópio como marco, em 1839, terminando apenas em 1949 com a fundação da República Popular da China. Durante tal período, as 
potências ocidentais submeteram o Império Chinês a diversos tipos de intervenções que ofendiam sua civilização e feriam sua soberania e integridade ${ }^{3}$ - como o bombardeio de portos, os impactos sociais do contrabando e uso disseminado de ópio, concessões territoriais e privilégios comerciais. Aos dirigentes políticos do Japão, observando as agressões à China e sob ameaça das potências imperialistas ocidentais, não restaria alternativa se não ceder às demandas de abertura comercial e à assinatura de tratados desiguais em 1858 (SARAIVA, 2008).

A dinâmica imperialista ocidental acabaria por redefinir a política mundial segundo o modelo de desenvolvimento europeu, projetando para as demais regiões do globo seus conceitos de soberania territorial e Estado, uma projeção do que seria a Europa. Como destacam Acharya e Buzan (2010), o imperialismo europeu causou grande impacto intelectual nas colônias, gravando entendimentos sobre as mentes e as práticas do mundo não europeu. Portanto, a partir da intensificação da presença ocidental na região da Ásia Oriental em meados do século XIX, China e Japão compreenderam o elevado grau de insegurança a que estavam submetidos, haja vista as estratégias de coerção utilizadas pelas potências europeias nos momentos de expansão. Sendo assim, as elites políticas de ambos os países tomaram a decisão de se adaptarem e adequarem suas instituições e estruturas à nova conjuntura vigente, absorvendo práticas e normas europeias.

Chineses e japoneses percebiam que o poder das potências ocidentais decorria de seu poderio econômico e militar, portanto estabeleceram o aumento do poder do Estado como prioritário. Ao final do século XIX, a China Qing conseguiu introduzir reformas pontuais, mas encontrou dificuldades por ter sido durante séculos o centro nervoso de um sistema regional, e o determinante das normas sociais desse sistema ${ }^{4}$. Além disso, a elite chinesa enxergava o padrão de interação europeu como bárbaro e contraditório - denominando-se civilizados, mas invadindo territórios de outras nações -, dificultando a aceitação do modelo de organização europeu como o ideal a emular (SUZUKI, 2009). Segundo Pumin (2014), os chineses patrocinaram um self-strenghning movement, que serviu apenas para preservar a dinastia Qing e que tinha o objetivo de fortalecer e modernizar as forças armadas do país, empenhando-se em fortalecer a ordem existente, agindo, então, de forma

3 Na obra Sobre a China, Henry Kissinger (2011) descreve de maneira esclarecedora as pressões das potências para abertura do país e as estratégias chinesas para lidar com os ocidentais.

4 A existência de um sistema interestatal asiático-oriental, ou um sistema sinocêntrico na Ásia, é discutida por Giovanni Arrighi na obra Adam Smith em Pequim (2008); Arrighi et al em The Resurgence of East Asia (2003); por Andre Gunder Frank na obra ReOrient (1998). 
oposta ao que se esperaria de uma China que estivesse em busca de se redefinir nos termos de um Estado moderno (PUMIN, 2014).

A elite japonesa da época enxergou no modelo europeu uma saída para se livrar da sensação de insegurança e da violência ocidental, e se lançou em um período de transformações intensas levadas adiante a partir da Restauração Meiji (1868). A adaptação japonesa teve alguns facilitadores: uma elite política mais aberta a reformas - haja vista a recente deposição do regime feudal pela liderança Meiji -, enquanto a liderança chinesa ainda trabalhava segundo a lógica institucional do Estado tradicional chinês; a menor extensão territorial japonesa colaborava para a implementação e efetividade das reformas, diferente da China com seu vasto território; ademais, havia no Japão um caráter ideológico nas reformas, que era o de fazer do país o centro da Ásia, posição ocupada antes pela China (SUZUKI, 2009). Esse processo de modernização, levado adiante pelo Japão, também internalizou a concepção europeia/ocidental de ordem internacional, assim como as práticas de caráter imperialista, expansionista e “civilizatório” (SUZUKI, 2009). Pode-se dizer que, nesse contexto, se deu a grande divergência entre China e Japão: o primeiro insistiu em um modelo institucional que já falhara ao conter o avanço ocidental, enquanto o segundo emulou seu “inimigo” e se aproveitou das vantagens alcançadas contra nações vizinhas. Logo, às potências ocidentais se somaria o Império Japonês, que buscava se estabelecer como potência e exigiria os mesmos privilégios comerciais e políticos cedidos pela China aos ocidentais.

A expansão japonesa na Ásia seria favorecida pelo contexto internacional do início do século XX. Na Europa, se vivenciava o declínio do equilíbrio de poder entre as potências - o que voltava a atenção dessas para a própria região, o que resultaria na deflagração da Primeira Guerra Mundial; posteriormente, o fracasso na busca por estabelecer uma ordem mundial pacífica no âmbito da Liga das Nações e o isolacionismo e resistência dos EUA em assumir o papel de potência no arranjo diplomático mundial. Com a atenção das potências voltadas ao Ocidente, o Japão teria maior liberdade para agir em sua região.

O Japão logo testou sua capacidade bélica - fruto da modernização que promovera - e se lançou em um processo de expansão territorial em conflitos com países vizinhos, entrando em guerra contra a China em 1894. Para Suzuki (2009), a Primeira Guerra Sino-Japonesa foi fundamentalmente um choque entre duas ordens internacionais; para Pumin (2014), foi uma competição significativa entre os dois países após uma geração de modernização, em que a derrota chinesa parecia inevitável, e que mudou a história do país. Tal conflito inaugurou uma 
série de agressões do Japão aos países vizinhos, entre eles a China, que ainda se refletem nas relações diplomáticas da atualidade. Tornou-se cada vez mais claro, com o passar das décadas, que o novo governo japonês cedera a um regime autoritário, dominado pela ala militar e por uma elite imperial, que intensificou ainda mais a violência contra os seus vizinhos asiáticos.

O Império do Japão foi à guerra contra o Império Chinês em 1894, acusando os chineses de violarem a Convenção de Tientsin de 1885 - que tratava da não interferência japonesa ou chinesa na política doméstica do então Reino da Coreia $^{5}$. A vitória japonesa sobre a China, em 1895, levou à subsequente sujeição e anexação da península coreana pelo Império Japonês por uma série de tratados no início do século $\mathrm{XX}^{6}$, abrindo caminho terrestre aos japoneses para o território chinês. Ao fim da guerra sino-japonesa, pelo Tratado de Shimonoseki ${ }^{7}$ (1895) o Império Chinês abdicara de qualquer tipo de influência sobre a península coreana, e foi obrigado a pagar indenizações de guerra ao Japão, conceder benefícios a comerciantes e navios em território e rotas fluviais chinesas de navegação, além de ceder ao Japão de forma perpétua a península de Liaodong e a ilha de Formosa (Taiwan). O Japão, assim como os ocidentais, tentara dividir o território chinês, e o papel do Japão na separação de Taiwan da China continental é lembrado até a atualidade.

Ao vencer a guerra contra a Rússia, em 1905, o Japão consolidou sua supremacia como potência no Leste Asiático. Com o vácuo deixado pelo Império Russo na região, a decadência da dinastia Qing e a recém-fundada República na China, e a guerra na Europa a partir de 1914, o Império Japonês desejou ir além e expandir seus domínios. Em segredo, os japoneses apresentaram aos chineses "Vinte e uma Demandas"8 que, em síntese, tinham o mesmo objetivo dos tratados de anexação da Coreia. O governo chinês, em posição inferior ao japonês nas negociações, aceitou grande parte das propostas - reconheceu a posição dominante

5 Uma versão na íntegra da Convenção de Tientsin de 1885 está disponível na página da National University of Singapore. Disponível em: < http://www.fas.nus.edu.sg/hist/eia/documents_archive/tientsin-convention.php > .

6 Os textos dos tratados entre Japão e Coreia estão disponíveis em: Tratado de Eulsa ou Tratado de Protetorado Japão-Coreia de 1905: < http://www.conservapedia.com/Eulsa_Treaty > ; Tratado de Anexação Japão-Coreia de 1907: < http://www.conservapedia.com/Japan-Korea_Annexation_Treaty_of_1907 > ; e o Tratado de Anexação Japão-Coreia de 1910: < http://www.conservapedia.com/Japan_Korea_Annexation_Treaty > .

7 O texto na íntegra do Tratado de Shimonoseki de 1895 pode ser encontrado em: < http://www.taiwandocuments. org/shimonoseki01.htm > .

8 Uma tradução e cobertura sobre o desenrolar das discussões sobre as demandas japonesas podem ser encontradas na página: < http://china.usc.edu/japanese-government- \% E2 \% 80 \% 9Ctwenty-one-demands \% E2 \% 80\% 9Dapril-26-1915> . 
do Japão na província de Shandong, no sul da Manchúria e na Mongólia Interior, além de aceitar a proibição de conceder ilhas e regiões costeiras a qualquer potência que não o Japão. Mas conseguiu rejeitar a demanda de entregar a administração chinesa a "conselheiros" japoneses (HUANG, 2015). Tais demandas japonesas foram tidas como outra humilhação contra o povo chinês, criando na população uma aversão significativa contra o Japão (HUANG, 2015). As agressões japonesas à China continuariam no decorrer das décadas.

Do ponto de vista doméstico japonês, a busca por transformar o país em potência demandava uma quantidade crescente de matérias-primas não suprida internamente. As reformas institucionais, econômicas, o esforço industrializante, o acentuado crescimento populacional, a construção e modernização da máquina de guerra, a proeminência dos militares no comando do país a partir da década de 1930, tais fatores impulsionaram os planos de expansão territorial do Império Japonês para a China e Sudeste Asiático (KENNEDY, 1987). Em 1931, o Japão iniciou a invasão da Manchúria e, em 1937, partiu violentamente para a conquista do território chinês, cujo episódio marcante foi a invasão da então capital chinesa Nanjing. O ataque a Nanjing pelos japoneses ficou conhecido por "Massacre" ou "Estupro", devido à violência perpetrada pelos soldados do exército imperial japonês, que saqueou e incendiou parte da cidade, promoveu execuções em massa de prisioneiros de guerra, além de torturar e assassinar milhares de civis - calculase que o exército japonês tenha executado entre 200 mil e 300 mil pessoas apenas em Nanjing. Entre os civis torturados e mortos na antiga capital, calcula-se que os japoneses estupraram de 20 mil a 80 mil mulheres chinesas, levando muitas à morte por ferimentos relacionados à violência sexual, ao suicídio ou a danos psicológicos graves (CHANG, 1998). O massacre em Nanjing9 foi apenas um episódio da invasão japonesa, que segundo Iris Chang10 - utilizando números de R. J. Rummel (1991) -, causou um total de mais de 19 milhões de mortes, diretas (assassinatos) e indiretas (como mortes por fome, doenças causadas por saques, bombardeios, experiências médicas).

A China esteve submetida durante cinco décadas à hostilidade japonesa - se levarmos em conta que essa se iniciou com a Primeira Guerra Sino-Japonesa, em

9 O massacre em Nanjing também foi tema de diversas obras cinematográficas, como City of Life and Death, de Lu Chuan (2009); The Flowers of War, de Zhang Yimou (2011); Nanking, de Bill Guttentag e Dan Sturman (2007).

10 Em sua obra The Rape of Nanking (1998), Iris Chang faz uma investigação minuciosa e interessante sobre o massacre japonês em Nanjing, colhendo documentos oficiais, jornais e filmagens da época, depoimentos de sobreviventes chineses e ex-soldados japoneses, assim como busca entender os motivos que levaram à violência sádica japonesa durante a invasão da China. 
1894, e se encerrou apenas com a rendição e retirada japonesa em 1945, quando se encerrou a Segunda Guerra Sino-Japonesa e o Japão foi obrigado a abdicar e retirar suas tropas do território chinês. Cinco décadas de submissão à "humilhação" japonesa se tornaria um forte elemento formador do nacionalismo chinês nas décadas posteriores, um elemento que, inclusive, vem se intensificando nessas últimas décadas.

\section{O sentimento anti-Japão fomentado}

Além da invasão pelos japoneses, a sociedade chinesa ainda encarava os problemas políticos domésticos do país. O fim da combalida dinastia Qing, a fundação da frágil República da China em 1912, uma intensa disputa pelo comando do país entre nacionalistas do Kuomintang e comunistas do Partido Comunista chinês, seriam fatores que comprometeriam a estabilidade doméstica e a unidade nacional. A China só poderia "respirar” após o sucesso da Revolução Chinesa e a fundação da República Popular da China, em 1949, tendo o Partido Comunista chinês vencido os nacionalistas na disputa pelo comando do país, e esses últimos se retirado para a ilha de Taiwan. Nas décadas posteriores à fundação da República Popular, o Partido Comunista chinês se ocupou da tarefa de reconstruir o país e fazer uma nova China, seguindo o objetivo de construir uma China socialista e moderna ${ }^{11}$.

Nessa fase inicial de estabelecimento da República Popular, o P.C. chinês poderia reivindicar a sua legitimidade como governante em duas bases, na ideologia marxista-leninista e no nacionalismo - e.g. focando na luta de classes representada pela disputa entre nacionalistas/capitalistas e comunistas, e argumentando ser o único responsável pela vitória sobre os japoneses, por isso sua "legitimidade patriótica” de estar no poder (CUI, 2012). Mas a preocupação primordial do Partido Comunista em se estabelecer como único governante legítimo do país contra o Kuomintang e construir o socialismo chinês parecem ter sido mais importantes nesse momento do que rememorar os episódios históricos da agressão japonesa (ZHANG; WEATHERLEY, 2013).

11 Para maiores detalhes sobre a história da Revolução Chinesa e o desenvolvimento político e econômico da República Popular da China, consultar: A Revolução Chinesa, de Wladimir Pomar (2004); A Construção do Socialismo na China, de Daniel Aarão Reis Filho (1982). 
Ainda assim, a figura do invasor japonês esteve presente na memória chinesa desde o pós-guerra, sobretudo nos discursos de retórica anti-imperialista. A maneira como os políticos chineses utilizaram essa figura variou em intensidade de acordo com o tempo e conjuntura doméstica. A construção social e transmissão de uma memória coletiva sobre a agressão japonesa - memória construída a partir de memórias vividas pela população somadas a memórias mediadas por representações, institucionalmente moldadas por processos de seleção e exclusão, lembranças ou “esquecimentos" - tiveram grande importância no desenvolvimento da relação sino-japonesa (CUI, 2012). Podemos dividir essa memória em duas fases: uma, quando ela esteve sob controle majoritário do Estado e, outra, quando o Estado passa a perder gradualmente o monopólio quase exclusivo sobre ela - na primeira, predomina o nacionalismo estatal (proposto por políticos e líderes em geral que almejam reforçar sua legitimidade, apelando ao patriotismo do povo) e, na segunda, quando predomina o nacionalismo popular (aquele impulsionado por intelectuais, jornalistas e escritores e focado em debates sobre história, cultura, "valores" nacionais etc.) (ROSE, 2000).

Naquela primeira fase, dentro da lógica do discurso do nacionalismo antiimperialista e das experiências recentes, o P.C. e o governo chinês utilizaram de representações e campanhas pedagógicas, como filmes e músicas, para fomentar o patriotismo nacional. Um dos componentes dessa propaganda era a memória da agressão japonesa e a narrativa vitoriosa do partido como "herói” triunfante no objetivo de livrar a China das garras dos "demônios japoneses”. Entre os recursos de propaganda, estavam filmes como Mine Warfare (1962) e Tunnel Warfare (1965), que retratam de maneira cômica a guerra de resistência contra o Japão e demonstram com clareza os tipos de personagens objetivados: um invasor japonês de estereótipo tolo, o traidor chinês que deveria ser desprezado e o guerrilheiro comunista como o herói inteligente (CUI, 2012; ZHANG; WEATHERLEY, 2013) filmes que são um exemplo da mescla de memória vivida com memória mediada institucionalmente. Mas aquele era um momento histórico particular, onde a ideologia marxista-leninista-maoísta ainda era forte componente da legitimidade do governo comunista, e esse governo tinha controle dos meios de informação e de educação. Em tal contexto, os líderes chineses utilizavam a educação patriótica, com elementos anti-Japão, destinada principalmente para fins políticos domésticos, e não um público externo (HE, 2007). Como resultado dessa memória histórica, estabeleceu-se uma imagem negativa do Japão na mentalidade de grande parte da população chinesa que viria à tona no futuro. 
Ao mesmo tempo em que fomentava o patriotismo internamente, o governo chinês adotava uma política externa pragmática, visando quebrar o isolamento do país - aprofundado após a ruptura sino-soviética no inicio da década de 1960 e os atritos com o vizinho comunista do norte. Tal pragmatismo é demonstrado na reaproximação e normalização das relações entre a República Popular com Estados Unidos e Japão durante a década de 1970. Durante o processo de normalização da relação com o Japão, o Estado chinês adotou uma política de separar o caráter majoritariamente pacífico da população japonesa do caráter perverso de poucos líderes do período da guerra (CUI, 2012). Durante o processo de normalização, o premier Zhou Enlai descreveu o povo japonês como pacífico e deu pouca atenção à questão da propriedade territorial de pequenas ilhas inabitadas localizadas entre Okinawa e Taiwan, chamadas Diaoyu em chinês e Senkaku em japonês ${ }^{12}$. O então primeiro-ministro chinês apontou que a questão da posse do arquipélago não era um problema quando comparado à recuperação de relações diplomáticas normais - questão que mais tarde provocaria intensas disputas entre os dois países (HE, 2007). Outra medida tomada para promover a normalização da relação sinojaponesa foi a renúncia chinesa por reparações de guerra por parte do Japão, como consta no comunicado conjunto entre os dois países de 1972 (JAPAN, 1972). O objetivo desse pragmatismo era conseguir do Japão o reconhecimento da República Popular da China como governo legítimo chinês, estimular o comércio bilateral e formar um alinhamento estratégico frouxo contra a União Soviética, todos objetivos concretizados (JAPAN, 1972). Na realidade, a normalização das relações com o Japão veio ao custo da omissão de fatos históricos da guerra entre os dois países, sem que houvesse um reconhecimento histórico mútuo sobre o que realmente aconteceu durante o conflito,

impediu a investigação rigorosa dos fatos históricos, e gestos políticos substituíram a restituição sincera e concreta. A tentativa de Pequim de criar uma ilusão de amizade sino-japonesa nos anos 1970 sem antes resolver a conta histórica foi muito bem sucedida. A maioria dos jovens chineses da época tinha um conhecimento mínimo sobre as atrocidades japonesas de guerra, pois os livros didáticos controlados pelo Estado raramente as mencionavam e a pesquisa acadêmica sobre esse tema foi banida. No entanto, histórias privadas sobre os "demônios japoneses" sobreviveram, mas apenas dentro

12 Tal arquipélago está localizado no Mar da China Oriental, a uma distância de aproximadamente 190 quilômetros a nordeste de Taiwan, a cerca de 290 quilômetros a oeste de Okinawa (Japão) e a aproximadamente 400 quilômetros da China continental. É formado por oito ilhas desabitadas que atualmente estão sob controle japonês. 
de famílias e pequenas comunidades. Além disso, devido ao firme controle dos meios de comunicação de massa naquele período, a população chinesa não possuía meios para conhecer o tratamento falso dado pelo Japão sobre a história da guerra, tal como o discurso acima mencionado proferido por Tanaka na Dieta, a omissão dos crimes de guerra nos livros didáticos e as visitas de líderes políticos ao Santuário de Yasukuni ${ }^{13}$ que posteriormente se tornou o ponto focal da discordância política sino-japonesa. (HE, 2007, p. 6 - tradução nossa) ${ }^{14}$

A fase majoritariamente positiva da relação seria passageira e a década de 1980 trouxe mudanças importantes na utilização do nacionalismo na China. O declínio progressivo da ideologia marxista-leninista nas décadas posteriores às políticas de reforma e abertura econômica levaram o Estado chinês e o Partido Comunista a progressivamente utilizarem o nacionalismo para preencher esse vazio ideológico e diversificar as bases de sua legitimidade (CUI, 2012; EKMAN; PAJON, 2015; YUAN, 2008; ZHANG; WEATHERLEY, 2013).

Quando a população chinesa passou a aceitar a amizade sino-japonesa, o governo chinês renovou a narrativa da guerra, na década de 1980. Isso ocorreu devido ao declínio da ideologia comunista já mencionado, e ao fato de que as reformas do então governo de Deng Xiaoping sofriam forte oposição da ala mais conservadora do Partido Comunista chinês e de parte da população que sentia os efeitos negativos das reformas que tomavam curso. Então, na nova estrutura de ideias legitimadoras do Partido que se estabelecera, o patriotismo passaria a ter função principal, onde se pregaria o amor pela nação e a grandeza da China, assim como o Partido Comunista se afirmaria como guardião do patriotismo.

13 O Santuário de Yasukuni foi criado em 1869, com o objetivo de “confortar os espíritos" e honrar a memória daqueles que lutaram e morreram pela causa imperial, entre eles os soldados japoneses mortos em guerra. Dentre os soldados homenageados, estão criminosos de guerra Classe A - julgados pelo Tribunal de Crimes de Guerra de Tóquio - que foram consagrados em 1978, entre eles o General Hideki Tojo. Por honrar a memória de tais indivíduos, o local é alvo de críticas dos países invadidos pelo Japão durante a Segunda Guerra Mundial. Governos da Coreia do Sul e China, por exemplo, alegam que as homenagens feitas a criminosos de guerra no santuário denotam um caráter nacionalista e militarista ainda presentes na sociedade japonesa. O local também abriga o museu militar Yushukan (SOUZA, 2015).

14 "prevented rigorous investigation of historical facts, and political gestures substituted sincere, concrete restitution. Beijing's attempt to create an illusion of Sino-Japanese friendship in the 1970s without first settling the historical account was largely successful. Most young Chinese at that time had minimal knowledge about Japanese war atrocities, for the state-controlled textbooks rarely mentioned them and academic research on this topic was banned. Private stories about the 'Japanese devils' nevertheless survived, but only within families and small communities. Moreover, because of the tightly controlled mass media at the time, ordinary Chinese people had no way to learn about Japan's false treatment of the war history, such as the aforementioned speech in the Diet by Tanaka, textbook cover-up of war crimes, and leaders' worship at the Yasukuni Shrine that later became the focal point of Sino-Japanese political contention” (HE, 2007, p. 6). 
A narrativa principal da guerra passou do conflito entre nacionalistas e comunistas para a resistência chinesa às invasões estrangeiras, sobretudo a invasão japonesa (HE, 2007). Os efeitos de se desconsiderar um entendimento histórico mútuo sino-japonês sobre os fatos da guerra tornaram-se evidentes a partir de então.

Em meados da década de 1980, o governo chinês passa a lançar campanhas patrióticas e instruir que as escolas primárias e secundárias enfatizassem o ensino da história de resistência à agressão estrangeira como uma forma de lembrar aos estudantes as lições históricas e para que não esquecessem a invasão imperialista e a heroica resistência do povo chinês. Os livros didáticos passam a "reabilitar" o papel do partido nacionalista Kuomintang na resistência ao Japão, enquanto passam a relatar de forma mais abrangente os crimes de guerra japoneses, com descrições vívidas, depoimentos de vítimas e imagens explícitas das crueldades. Museus são construídos em importantes locais do conflito e designados como bases de educação patriótica, como o Nanjing Massacre Memorial Hall e o museu da Unidade 731, em Harbin; com permissão e apoio governamental, são efetuadas pesquisas históricas aprofundadas sobre o período de guerra; são produzidos filmes sobre o conflito, como os que relatam o massacre de Nanjing e os experimentos médicos feitos em prisioneiros de guerra ${ }^{15}$ (HE, 2007).

O primeiro efeito popular dessa nova abordagem legitimadora do Estado chinês e sobre sua base histórica referente à guerra contra o Japão verificou-se em 1982, com a questão do tratamento sobre a história da guerra nos livros didáticos japoneses. Tal questão emergiu após a mídia japonesa divulgar que o Ministério da Educação japonês recomendara mudanças a historiadores e editores de livros didáticos de história. A instrução era eliminar, reformular ou atenuar passagens relacionadas com as ações japonesas durante o período colonial e de guerra na Ásia - mudanças quanto à descrição da "invasão da China” (trocada por "avanço sobre a China”) pelo Japão e descrições sobre o Massacre de Nanjing. A mídia de diversos países asiáticos reproduziu e reforçou as críticas da mídia japonesa, e o governo chinês fez um protesto oficial demandando que os livros didáticos fossem corrigidos. O governo chinês argumentou que, ao minimizar ou omitir a natureza das ações japonesas durante a guerra contra a China, o governo do Japão não adotava uma visão correta da história, algo prejudicial para as relações sinojaponesas. A imprensa chinesa promoveu, durante dois meses, comentários de líderes de organizações de massa (como China-Japan Friendship Association, China

15 Nanjing Massacre (1982), Bloody Testimony of Massacre in a Captured City (1987), Men Behind the Sun (1988) (HE, 2007). 
Education Society, All-China Youth Federation), juristas e acadêmicos chineses; entrevistas com sobreviventes e testemunhas da conduta japonesa; programas televisivos mostraram imagens das atrocidades; foram realizadas exposições fotográficas retratando os acontecimentos da guerra em diversas cidades da China. A atitude do governo japonês foi encarada como uma distorção e "embelezamento" da história da guerra (ROSE, 2005). Foi a primeira vez, desde a guerra, que a China contestou, ou teve problemas, com os pontos de vista históricos do Japão (HE, 2007), e tais discordâncias se intensificariam no decorrer das décadas.

Ainda durante a década de 1980, protestos do governo e da população chineses voltaram a ocorrer por ações e políticas japonesas: em 1985, contra a visita do primeiro-ministro japonês Yasuhiro Nakasone à Yasukuni e protestos estudantis devido ao grande fluxo de produtos japoneses no mercado doméstico chinês, o que foi chamado de "segunda invasão japonesa"; a questão sobre livros didáticos de história no Japão teria outro capítulo no ano de 1986; o aumento dos gastos em defesa do Japão e a tensão devido ao desequilíbrio comercial contínuo entre os dois países em 1987; declarações controversas sobre a guerra por parte de líderes políticos japoneses em 1988 e 1989 (ROSE, 2005). Embora o Estado chinês tenha mantido a postura de distinguir a população japonesa dos líderes que levaram o Japão à guerra - buscando evitar um antagonismo contra o Japão, com quem a cooperação econômica já se tornara importante para os interesses nacionais chineses -, os protestos populares na China demonstravam que parecia estar se substanciando na mentalidade da população chinesa a crença na culpa coletiva ou na "maldade" de toda nação japonesa durante a guerra. Além disso, movimentos civis chineses, que reivindicavam reparações de guerra do governo e de corporações japonesas, começaram a ganhar força nos anos finais da década de 1980, compostos por sobreviventes chineses de agressões diversas, como de trabalhos forçados, exposição a armas químicas, escravização sexual (CUI, 2012; HE, 2007) - reparações de que o governo chinês abdicara quando houve a normalização das relações sino-japonesas. Tais atritos seriam interpretados como naturais, não tivessem se originado após a normalização das relações, demonstrando que, ao ignorar a resolução de controvérsias históricas como fator crucial na normalização, o conflito findado em 1945 ainda lançaria sombras sobre o futuro da relação.

No início dos anos de 1990, o governo comunista chinês avançou com maior rapidez na disseminação de uma campanha de educação patriótica nas escolas ${ }^{16}$,

16 Para maiores detalhes sobre a educação patriótica, tanto na China quanto no Japão, consultar Sneider, 2013. 
com o objetivo de fornecer aos jovens chineses uma versão da história que reduzia a importância da narrativa da era maoísta da luta de classes dentro da China, em favor de uma versão que representava a China como vítima da humilhação e brutalidade das potências estrangeiras, como afirma Sneider:

Agora a ênfase está na unidade nacional, embora liderada pelos comunistas, contra o inimigo estrangeiro. A afirmação do papel da China como arquiteto da derrota japonesa agora é central, juntamente com a vitimização da China nas mãos de um invasor brutal e criminoso. É uma narrativa que se adequa à mobilização nacionalista de uma população não mais motivada pela ideologia neocomunista. (SNEIDER, 2013, p. 41 - tradução nossa) ${ }^{17}$

Muitos intelectuais chineses, durante a década de 1990, argumentavam abertamente que o marxismo-leninismo já não era um meio efetivo de garantir lealdade e prevenir a desintegração da sociedade chinesa, apontando que o país deveria se basear firmemente sobre o nacionalismo, capaz de fornecer a base para a coesão nacional e integração política (CUI, 2012). As campanhas de educação patriótica promovidas pelo Estado chinês facilitaram a emergência de um forte nacionalismo cultural (ou nacionalismo popular) durante a década de 1990, pois se produziu um ambiente mais relaxado e propício para debates sobre a história e a identidade nacional (ROSE, 2000). Uma série de publicações e revistas de caráter nacionalista e antiocidental ganharia espaço durante a década de 1990. A introdução da internet e sua popularização nos anos 2000 trouxe a possibilidade para que parte da sociedade chinesa, educada segundo a educação patriótica iniciada nos 1980, pudesse se expressar e se comunicar, uma ferramenta ideal para a construção e reconstrução da memória coletiva em escala massiva. O ciberespaço chinês se transformaria rapidamente em uma plataforma popular efetiva de mobilização nacionalista, particularmente de um nacionalismo antiJapão (CUI, 2012).

Na década de 1990, o peso das divergências históricas continuaria, mas um novo fator ganharia peso: a disputa territorial pelo arquipélago Diaoyu/Senkaku, mencionado anteriormente. Mais uma questão deixada de lado durante o processo de reaproximação entre China e Japão veio à tona para desestabilizar a relação

17 "Now the emphasis is on national unity, though led by the Communists, against the foreign foe. The assertion of China's role as the architect of Japan's defeat is now central, along with China's victimization at the hands of a brutal and criminal invader. It is a narrative that suits the nationalist mobilization of a populace no longer motivated by neo-Communist ideology" (SNEIDER, 2013, p. 41). 
diplomática sino-japonesa. A reivindicação, pelos dois países, sobre a soberania das ilhas seria fomentada pela presença de recursos energéticos no leito marítimo da região disputada, além de possibilitar ao país que as controlasse a expansão de sua Zona Econômica Exclusiva18. Mas os sentimentos seriam inflamados por grupos nacionalistas de ambos os países: ora grupos japoneses desembarcaram nas ilhas, ora grupos chineses, levando os dois governos a se expressarem de forma assertiva sobre a soberania das ilhas. A disputa territorial se tornou problema recorrente, tendo gerado crises entre os dois países em 1990, 1996, 2004-2005, 2010 e $2012^{19}$ (BEUKEL, 2011). Durante as crises dos 1990, o governo chinês ainda possuía maior controle sobre os meios de informação e conseguiu promover blackouts midiáticos, visando evitar protestos e conter uma escalada da disputa que ofuscasse as boas relações bilaterais sino-japonesas - nesse período, os grupos nacionalistas chineses tinham como base Hong Kong e Taiwan, onde os protestos aconteciam (BEUKEL, 2011)). A situação mudou nos anos 2000, quando parte expressiva da população chinesa passou a ter a internet como fonte de informações e ferramenta de expressão - o número de usuários de internet na China saltou de cerca de 22 milhões em 1997 para 298 milhões em 2008 (CUI, 2012), tendo alcançado cerca de 688 milhões de usuários em 2016, segundo órgão responsável do Estado chinês (CHINA, 2016).

\section{Reflexos do sentimento anti-Japão na relação bilateral}

A abertura e diversificação midiática na China possibilitaram maior liberdade de expressão e difusão de informações sobre ressentimentos e inquietações populares. Assim, notícias negativas sobre o Japão, com potencial para provocar sentimentos antijaponeses, podem ser obtidas por fontes alternativas de informação, além daquelas oficiais. O público chinês também está mais bem informado sobre as negociações diplomáticas entre os dois países, fator que causa pressão sobre o governo chinês quando se busca acordos e compromissos. Após ser intensamente exposta, com a campanha de educação patriótica, a detalhes

\footnotetext{
18 Para mais detalhes sobre origem, afirmações e controvérsias da disputa pelo arquipélago Diaoyu/Senkaku, consultar: Thomas A. Hollihan, The Dispute over the Diaoyu/Senkaku Islands (2014); Zhongqi Pan, Sino-Japanese Dispute over the Diaoyu/Senkaku Islands (2007); Shin Kawashima, The Origins of the Senkaku/Diaoyu Islands Issue (2013).

19 Para uma descrição detalhada dessas crises, consultar Beukel, 2011.
} 
das atrocidades cometidas pelo exército japonês durante a guerra, a sociedade chinesa se tornou altamente receptiva e reativa a notícias ou rumores negativos que envolvam o Japão ou a sociedade japonesa (HE, 2007). O número crescente de páginas nacionalistas e de mensagens anti-Japão se expandiram com o uso da internet e a popularidade de redes sociais como o SinaWeibo, além de facilitarem o encontro entre nacionalistas que antes estavam isolados, possibilitaram a proliferação de grupos de discussão nacionalistas, em parte explicando o reforço dos sentimentos negativos quanto ao Japão (EKMAN; PAJON, 2015). Tornou-se usual a elaboração de petições online de grupos chineses com demandas variadas - e.g. no ano 2003 mais de um milhão de chineses responderam a uma petição que demandava desculpas e compensações do Japão por cidadãos feridos devido ao vazamento de armas químicas deixadas em território chinês após o término da guerra; no mesmo ano, uma petição online pedindo o boicote de uma marca de cerveja japonesa conseguiu 1,28 milhões de assinaturas em duas horas; ainda em 2003, cerca de um milhão de chineses assinaram, em dez dias, uma petição contra a participação de empresas japonesas na construção de trens de alta velocidade na China; em 2005, mais de dez milhões assinaram petição contra a campanha japonesa pelo assento permanente no Conselho de Segurança da ONU (EKMAN; PAJON, 2015).

Tal sentimento negativo quanto ao Japão ficou evidente nas reações populares às crises sobre o arquipélago Diaoyu/Senkaku nos anos de 2004-2005, 2010 e 2012, quando os protestos passaram a crescer em números a cada crise diplomática. A colisão na região disputada de embarcações chinesas com embarcações da marinha japonesa em 2004 (ASIA TIMES, 2004; BBC, 2005) e 2010 (WASHINGTON POST, 2010) e a detenção dos tripulantes chineses geraram uma onda de protestos anti-Japão por toda a China (CHINA DAILY, 2005; LA TIMES, 2010). Protestos coordenados pela internet, sem liderança clara, levaram centenas de milhares a protestarem em mais de quarenta cidades chinesas durante semanas, havendo protestos diante da embaixada do Japão em Beijing e ataques a estabelecimentos comerciais de origem japonesa em várias cidades da China (BEUKEL, 2011). Manifestações do tipo se repetiram em maior escala no ano de 2012, após o Estado japonês nacionalizar algumas ilhas do arquipélago - comprando-as de um proprietário particular japonês (REUTERS, 2012). Novamente, a violência foi demonstrada contra empresas de origem japonesa boicotadas e atacadas, assim como contra a embaixada japonesa em Beijing (CS MONITOR, 2012). Devido ao aumento da violência nos protestos populares, o governo chinês passou a interferir 
e buscar conter as manifestações. Campanhas de "patriotismo racional" foram divulgadas pelo governo e mídia oficial, afirmando ser necessário sabedoria na expressão do patriotismo, não devendo ser perturbada a ordem social do país (XINHUA, 2012). Medidas para conter a propagação de atos violentos foram tomadas (CS MONITOR, 2012a), como o controle de mídias sociais e programação de TV, campanha interna do Partido Comunista para que membros do governo não incentivassem as manifestações, prisões, publicidade de julgamentos e condenações de manifestantes que cometeram violência (EKMAN; PAJON, 2015).

Yinan He (2007) aponta o caso do projeto da ferrovia de alta velocidade BeijingShanghai como uma ilustração para o potencial dano às relações econômicas bilaterais que o nacionalismo e o sentimento anti-Japão da população chinesa podem causar. Após anos de debates sobre qual tecnologia se adaptaria melhor às necessidades chinesas, em 2003 a tecnologia do shinkansen japonês parecia ser a mais cotada a ser adotada no projeto de US $\$ 15$ bilhões. A perspectiva de que a tecnologia japonesa seria a vencedora da licitação foi veiculada em jornais de Hong Kong e petições online começaram a ganhar assinaturas em oposição à possível escolha do "trem-bala" japonês, devido às resistências do Japão quanto ao reconhecimento das agressões passadas (HE, 2007). Uma campanha nacionalista na internet foi organizada com o logotipo: “Céu e Terra não tolerarão traidores. Nós não queremos o trem-bala japonês. Nós nos recusamos à utilização de produtos japoneses na linha Beijing-Shanghai”, tendo a petição lançada por tal grupo alcançado noventa mil assinaturas em uma semana (GRIES, 2005). Para Yinan He, a pressão pública obrigou o governo chinês a reconsiderar as consequências políticas da decisão de adotar a tecnologia japonesa. Quando a ministra dos Transportes do Japão viajou à China para reforçar a proposta japonesa, não conseguiu se reunir com o primeiro-ministro chinês Wen Jiabao ou funcionários de alto escalão do Ministério das Ferrovias da China. Segundo He, Beijing deixou claro que, apesar dos aspectos técnicos e financeiros, o fator político também era importante na tomada de decisão. Durante a visita de uma delegação do parlamento japonês à China, o vice-ministro de Relações Exteriores da China sugeriu que seria necessário excluir o Japão do projeto devido à pressão da opinião pública, alegando que a China enfrentava um alto sentimento anti-Japão, e que, caso o governo adotasse a tecnologia do shinkansen, o povo chinês teria uma opinião negativa (HE, 2007).

Como demonstrado pelo caso acima, esse sentimento anti-Japão, que permeia parte da sociedade chinesa, gera consequências que vão além do descontentamento da população com o país vizinho, afetando a relação comercial entre os dois países 
no auge das crises diplomáticas. Como exemplo, relatórios do Bank of Japan²0, referentes ao segundo semestre de 2012 - o auge da crise pela nacionalização das ilhas mencionadas acima -, apontam que as discordâncias bilaterais foram responsáveis por uma queda drástica na exportação de veículos japoneses para a China. Segundo relatório da Japanese External Trade Organization (JETRO), de setembro a dezembro de 2012, a venda de automóveis produzidos no Japão para a China sofreu uma queda de $63 \%$ quando comparada com o mesmo período do ano anterior. As manifestações contra políticas japonesas foram um dos principais motivos citados para que tal queda acontecesse (JAPAN, 2013). A queda nas exportações de veículos para o mercado chinês se deve, em parte, ao boicote de cidadãos chineses às empresas automotivas japonesas (TOKYO TIMES, 2012).

Houve também uma diminuição no número de turistas chineses que viajaram ao Japão no segundo semestre de 2012. Quando observados atentamente, os dados disponibilizados pela Japan Tourism mostram uma expressiva queda dessas viagens a partir de setembro de 2012, quando os desentendimentos bilaterais se agravaram, contrariando as tendências dos meses e anos anteriores. Na comparação mensal entre os anos de 2011 e 2012, houve aumento de turistas chineses que visitaram o Japão em todos os meses até setembro de 2012 e, a partir de outubro, há uma queda expressiva no comparado dos meses ano a ano (JAPAN TOURISM, 2013). Além de queda na demanda, agências de viagens chinesas cancelaram voluntariamente os pacotes de turismo que já haviam sido vendidos com destino ao país vizinho (BLOOMBERG, 2012). Possíveis boicotes chineses ao turismo no Japão podem ter impactos significativos no setor, uma vez que os chineses estão entre as nacionalidades que mais visitam e gastam no Japão - em 2015, foram a nacionalidade que mais visitou o arquipélago japonês, correspondendo a um quarto do total de visitantes estrangeiros e, de longe, os turistas que mais gastam no mercado japonês, sendo responsáveis por 40,8\% do total de gastos por turistas estrangeiros no Japão (JAPAN TIMES, 2016; JAPAN TOURISM, 2016).

Estatísticas disponibilizadas pela pesquisa The 11th Japan-China Public Opinion Poll, sobre as impressões mútuas entre os dois povos, demonstram o aumento da impressão negativa da população chinesa sobre o Japão desde 2007. No ano de 2013 - após a nacionalização de ilhas do arquipélago Diaoyu/Senkaku -, a impressão negativa sobre o Japão foi citada por cerca de $93 \%$ dos entrevistados

20 Os relatórios do Bank of Japan (BoJ), onde analistas apontam os efeitos dos atritos diplomáticos na economia e turismo no ano de 2012, podem ser encontrados no Monthly Report of Recent Economic and Financial Developments, December 2012. Disponível em: < http://www.boj.or.jp/en/mopo/gp_2012/gp1212b.pdf > . 
chineses, havendo um recuo nessa percepção nos anos seguintes, atingindo $78 \%$ em 2015. Quando questionados sobre as razões para a impressão desfavorável em relação ao Japão, cerca de $70 \%$ dos chineses entrevistados mencionaram a falta de remorso e de um pedido de desculpas adequado do Japão no tocante à história da invasão da China; a nacionalização japonesa das ilhas do arquipélago Diaoyu/Senkaku também foi lembrada por cerca de $68 \%$ dos entrevistados, sendo essas duas razões proeminentes em comparação às demais. Quando perguntados sobre as principais barreiras para o desenvolvimento da relação bilateral, as razões mais citadas pelos chineses foram a questão territorial e o entendimento e ensino da história no Japão; para $47 \%$ dos chineses entrevistados, a relação entre os dois países não se desenvolverá se as questões históricas não forem resolvidas (GENRON NPO; CHINA DAILY, 2015).

Após os violentos protestos antijaponeses de 2012, é perceptível a postura mais cautelosa do governo chinês ao tratar das questões históricas com o Japão, supostamente como medida para evitar atos de violência e vandalismo como os vistos outrora. Desde então, ao se manifestar sobre questões históricas, a chancelaria chinesa tem declarado que tais questões têm uma relação direta com a base política da relação bilateral, recordando o sofrimento causado pelo militarismo japonês, apontando a necessidade de que o Japão encare esse período e mantenha em mente as lições da história, permitindo que o país desenvolva boas relações com a região. Tal cautela pode ser um dos fatores responsáveis pelo recuo da percepção negativa da população chinesa sobre o Japão desde 2012, que podemos caracterizar como o período de maior tensão na relação bilateral recente.

A questão histórica pendente entre China e Japão se torna mais preocupante em um contexto de transformações de ordem regional e mundial em que as duas nações buscam assegurar sua relevância, tendendo a aumentar as desconfianças recíprocas sobre questões militares. A recente expansão e modernização das Forças Armadas chinesas geram apreensão entre os japoneses pela dúvida sobre qual seria a postura de uma China hegemônica e com uma sociedade com forte sentimento antijaponês. Por outro lado, a China se inquieta sobre a possibilidade de uma remilitarização do Japão - com uma eventual queda ou reinterpretação da constituição pacifista do país - que leve novamente o país a condutas agressivas contra seus vizinhos asiáticos. Embora a importante relação econômica bilateral mantenha-se estável e a relação diplomática esteja se normalizando nos últimos anos, ao que parece, pouco tem sido feito ou divulgado pelos dois Estados para superar as discordâncias referentes à história da guerra. Os problemas recentes da 
relação sino-japonesa são, em grande parte, reflexos da escolha política de deixar de lado o esclarecimento dos fatos históricos e a resolução de controvérsias sobre tais fatos no processo de reaproximação durante a década de 1970. Ao não se criar entre os dois povos uma versão comum sobre a história do conflito que os envolveu, abriu-se o precedente para que grupos dentro dos dois Estados criassem versões dos fatos que estivessem de acordo com seus interesses. Em um contexto de desenvolvimento e avanço das redes de informação e comunicação, em que o nacionalismo popular ganha forças e capacidade de mobilização devido ao seu alcance, a solução das divergências históricas se tornou um desafio ainda maior e urgente. Como verificado, postergar um acordo sobre tais desentendimentos amplia o risco de que as relações bilaterais deteriorem, ameaçando não apenas a estabilidade econômica entre os dois países, mas a segurança e a economia regionais.

\section{Referências}

ACHARYA, Amitav; BUZAN, Barry. Why is there no non-Western international relations theory? An introduction. In: ACHARYA, A.; BUZAN, B. (Edit.). Non-Western International Relations Theory Perspectives on and beyond Asia,. London: Routledge, 2010, p. 1-26.

ARRIGHI, G.; HAMASHITA, T.; SELDEN, M. The Ressurgence of East Asia: 500, 150 and 50 year perspectives. London: Routledge Curzon, 2003.

ARRIGHI, Giovanni. Adam Smith em Pequim: origens e fundamentos do século XXI. São Paulo, Boitempo Editorial, 2008.

ASIA TIMES. New Sino-Japanese strain over disputed islands. Asia Times Online, 27 mar. 2004. Disponível em: < http://www.atimes.com/atimes/Japan/FC27Dh01.html > . Acessado em: 05/05/2016.

BBC. Thousands join anti-Japan protest. BBC News, 16 abr. 2005. Disponível em: < http://news.bbc.co.uk/2/hi/asia-pacific/4450975.stm > . Acessado em: 05/05/2016.

BEUKEL, Erik. Popular Nationalism in China and the Sino-Japanese Relationship: the conflict in the East China Sea an introductory study. DIIS Report, Danish Institute for International, Copenhagen, n.01, 2011.

BLOOMBERG. Japan Sees 20\% Drop in China Tourism as Islands Row Heats Up. Bloomberg News, 13 set. 2012. Disponível em: < http://www.bloomberg.com/news/2012-09-13/ japan-fears-20-drop-in-china-tourists-as-islands-spat-heats-up.html > . Acessado em: $09 / 05 / 2016$. 
CHANG, Iris. The Rape of Nanking: the forgotten holocaust of World War II. New York: Basic Books, 1998.

CHINA. The 37th Statistical Report on Internet Development in China. China Internet Network Information Center (CNNIC). Disponível em: < http://cnnic.com.cn/IDR/ ReportDownloads/ > . Acessado em: 17/03/2016.

CHINA DAILY. 42 held for protest property damage. China Daily, 27 abr. 2005. Disponível em: < http://www.chinadaily.com.cn/english/doc/2005-04/27/content_437776.htm > . Acessado em: 05/05/2016.

CS MONITOR. Japanese shops, factories close in China after violence. The CS Monitor, 17 set. 2012. Disponível em: < http://www.csmonitor.com/Business/Latest-NewsWires/2012/0917/Japanese-shops-factories-close-in-China-after-violence > . Acessado em: 06/05/2016.

CS MONITOR. China moves to quell anti-Japanese demonstrations. The CS Monitor, 17 set. 2012a. Disponível em: < http://www.csmonitor.com/World/2012/0917/ China-moves-to-quell-anti-Japanese-demonstrations > . Acessado em: 06/05/2016.

CUI, Shunji. Problems of Nationalism and Historical Memory in China's Relations with Japan. Journal of Historical Sociology, Oxford, v.25, n.2, June 2012 p.200-222.

EKMAN, Alice; PAJON, Céline. Nationalism in China and Japan and Implications for Bilateral Relations. Asie.Visions -Institut Français des Relations Internationales (Ifri). Paris, March 2015.

FRANK, Andre Gunder. ReORIENT: global economy in the Asian Age. Los Angeles: University of California Press, 1998.

GENRON NPO, The; CHINA DAILY. The 11th Japan-China Public Opinion Poll: Analysis Report on the Comparative Data. Tokyo, 2015.

GRIES, Peter H. Chinese Nationalism: Challenging the State?. Current History, Philadelphia, v. 104, issue 683, Sept. 2005, p. 251-256.

HE, Yinan. History, Chinese Nationalism and the Emerging Sino-Japanese Conflict. Journal of Contemporary China, Oxford, v.16, issue 50, February 2007, p. 1-24.

HOLLIHAN, T. (Ed.). The Dispute Over the Diaoyu/Senkaku Islands: How Media Narratives Shape Public Opinion and Challenge the Global Order. Palgrave Macmillan US, 2014.

HUANG, Yanzhong. China, Japan, and the 21 Demands. The Diplomat Magazine. January 24, 2015. Disponível em: < http://thediplomat.com/2015/01/china-japan-and-the21-demands / > . Acessado em: 03/12/2015.

JAPAN. Joint Communique of the Government of Japan and the Government of the People's Republic of China, Ministry of Foreign Affairs of Japan (MOFA), 1972. < http://www.mofa.go.jp/region/asia-paci/china/joint72.html > Acessado em: 05/02/2016. 
JAPAN. JETRO survey: Analysis of Japan-China Trade in 2012 and outlook for 2013, Japanese External Trade Organization (JETRO) 2013. Disponível em: < http://www. jetro.go.jp/en/news/releases/20130219452-news > . Acesso em: 17/05/2014.

JAPAN TOURISM. Statistic of visitors to Japan from overseas, Historical Statistics, 2013. Disponível em: < http://www.tourism.jp/en/statistics/inbound/ > .

JAPAN TIMES. Visitors to Japan surge to record 19.73 million, spend all-time high $¥ 3.48$ trillion. The Japan Times News, 19 jan. 2016. Disponível em: < http://www. japantimes.co.jp/news/2016/01/19/national/japan-sets-new-inbound-tourism-record2015-comes-just-short-20-million-target/\#.V-Pbx4grLIU > . Acessado em: 01/06/2016.

KAWASHIMA, Shin . The Origins of the Senkaku/Diaoyu Islands Issue: The period before normalization of diplomatic relations between Japan and China in 1972. Asia-Pacific Review, Vol. 20, issue 2, 2013, p. 122-145.

KENNEDY. Paul M. The rise and fall of the great powers: economic change and military conflict from 1500 to 2000. New York, Random House, 1987.

KISSINGER, Henry. Sobre a China. Rio de Janeiro: Objetiva, 2011.

LA TIMES. Thousands in Chinese provinces stage anti-Japan protest. Los Angeles Times, 18 out. 2010. Disponível em: < http://articles.latimes.com/2010/oct/18/world/lafg-china-japan-protests-20101018 > . Acessado em: 06/05/2016.

PAN, Zhongqi. Sino-Japanese Dispute over the Diaoyu/Senkaku Islands: The Pending Controversy from the Chinese Perspective. Journal of Chinese Political Science, Vol. 12, Issue 1, April 2007, p. 71-92.

POMAR, Wladimir. A Revolução Chinesa. São Paulo: Editora Unesp, 2004.

PUMIN, Yin. The Defeat That Changed China’s History. Beijing Review, Beijing, Vol. 57, 34, Aug. 2014, p. 14-19.

REIS FILHO, Daniel Aarão. A Construção do Socialismo na China. São Paulo: Brasiliense, 1982.

REUTERS. Japan buys disputed islands. China sends patrol ships, Reuters New Agency, 11 set. 2012. Disponível em: < http://www.reuters.com/article/us-japan-chinaidUSBRE88A0GY20120911 > . Acessado em: 06/05/2016.

ROSE, Caroline. 'Patriotism is not taboo': nationalism in China and Japan and implications for Sino-Japanese relations. Japan Forum, Oxford, v.12, issue 2, March 2000, p. 169-181. ROSE, Caroline. Interpreting History in Sino-Japanese Relations: a case study in political decision-making. London and New York: Routledge, 2005.

RUMMEL, R.J. China's Bloody Century: Genocide and Mass Murder Since 1900. New Brunswick: Transaction, 1991

SARAIVA. José Flávio Sombra (org). História das relações internacionais contemporâneas: da sociedade interacional do Século XIX a era da globalização. São Paulo, Editora Saraiva, 2008. 
SIMOES, A.J.G; HIDALGO, C.A. The Economic Complexity Observatory: An Analytical Tool for Understanding the Dynamics of Economic Development. Workshops at the Twenty-Fifth AAAI Conference on Artificial Intelligence, 2011. Disponível em: < http://atlas.media.mit.edu/en/ > . Acessado em: 21/10/2016.

SNEIDER, D. Textbooks and Patriotic Education: Wartime Memory Formation in China and Japan. Asia-Pacific Review, Vol. 20, No. 1, 2013, p.35-54.

SOUZA, H.P. A relação diplomática sino-japonesa no contexto das celebrações dos 70 anos do fim da Segunda Guerra Mundial na Ásia. In: IV SIMPORI - Simpósio de Pós-Graduação em Relações Internacionais do Programa "San Tiago Dantas” (UNESP, UNICAMP e PUC/SP), 2015, São Paulo. Anais eletrônicos. Disponível em: < http://www.santiagodantassp.locaweb.com.br/novo/images/simposio/artigos2015/ PAULINO_A\%20relacao.pdf > . Acesso em: 28/03/2016.

SUZUKI, Shogo. Civilization and empire: China and Japan's encounter with European international society. New York: Routledge, 2009.

TOKYO TIMES. China's Boycott Hurts Japanese Car Makers: “This Is Politics, Not Business”, The Tokyo Times, 2012. Disponível em: < http://www.tokyotimes.com/ 2012/chinas-boycott-hurts-japanese-car-makers-this-is-politics-not-business / > . Acessado em: 09/05/2016.

WASHINGTON POST. Boat collision sparks anger, breakdown in China-Japan talks. Washington Post, 20 set. 2010. Disponível em: < http://www.washingtonpost. com/wp-dyn/content/article/2010/09/20/AR2010092000130.html > . Acessado em: 06/05/2016.

XINHUA. Wisdom Needed in the Expression of Patriotism. News Agency Xinhua, 16 set. 2012. Disponível em: < http://news.xinhuanet.com/english/indepth/2012-09/16/ c_131853756.htm > . Acessado em: 07/05/2016.

YUAN, Jing-Dong. Chinese Nationalism and Sino-Japanese Relations. Pacific Focus, Vol. XXIII, No. 2, August 2008, p. 212-231.

ZHANG, Qiang; WEATHERLEY, Robert. Owning up to the past: the KMT's role in the war against Japan and the impact on CCP legitimacy. The Pacific Review, Vol. 26, No. 3, 2013, p. 221-242. 